\title{
Effects of Captopril on Forearm Oxygen Consumption during Dynamic Handgrip Exercise in Patients with Congestive Heart Failure
}

\author{
Tsutomu Imaizumi, M.D., Akira Takeshita, M.D., \\ Naonori Nakamura, M.D., Kikuo SakaI, M.D., \\ Yoshitaka Hirooka, M.D., Satoshi Suzuki, M.D., \\ Megumu Yoshida, M.D., and Motoomi Nakamura, M.D.
}

\section{SUMMARY}

The maximal exercise capacity of patients with congestive heart failure (CHF) is frequently decreased because of decreased skeletal muscle oxygen utilization. In this study we examined whether forearm oxygen utilization is decreased during dynamic handgrip exercise in patients with CHF and whether captopril improves forearm oxygen utilization. They were divided into 3 groups according to the level of plasma renin activity (PRA) and New York Heart Association functional classification (NYHA): Group 1 consisted of 7 normal (control) subjects (PRA: $0.5 \pm 0.2 \mathrm{ng} / \mathrm{ml} / \mathrm{h}$, NYHA: 0); Group 2, 7 patients with severe CHF (PRA: $11.3 \pm 3.9 \mathrm{ng} / \mathrm{ml} / \mathrm{h}, \mathrm{NYHA}: 3.6 \pm 0.3$ ); Group 3, 4 patients with mild CHF (PRA : $2.4 \pm 0.2 \mathrm{ng} / \mathrm{ml} / \mathrm{h}, \mathrm{NYHA}: 2 \pm 0$ ). Forearm blood flow was measured by a strain gauge plethysmograph at rest and during dynamic handgrip exercise. Regional arterial venous oxygen content was measured and forearm oxygen consumption was calculated by the Fick principle. Forearm blood flow was less $(p<0.05)$ at rest and during exercise in patients with severe CHF than in control subjects; this was compensated for by increased oxygen extraction, thus maintaining forearm oxygen consumption at a normal level at rest and during submaximal exercise. During maximal exercise, oxygen extraction was not different between normal control subjects and patients with severe $\mathrm{CHF}$, thus forearm oxygen consumption was significantly less $(\mathrm{p}<0.01)$ in patients with severe CHF than in control subjects. In patients with mild CHF, forearm blood flow, oxygen extraction and oxygen consumption were not different from those in normal control subjects. Captopril (25 $\mathrm{mg}$ orally) did not alter forearm hemodynamics at rest and during exercise in control subjects and patients with mild CHF. In patients with severe CHF, captopril lowered systolic and mean blood pressure

From the Research Institute of Angiocardiology and Cardiovascular Clinic, Faculty of Medicine, Kyushu University, Fukuoka, Japan.

Address for correspondence: Akira Takeshita, M.D., Research Institute of Angiocardiology and Cardiovascular Clinic, Faculty of Medicine, Kyushu University, 3-1-1 Maidashi, Higashi-ku, Fukuoka 812, Japan.

Received for publication July 21, 1989.

Accepted May 11, 1990. 
$(p<0.05)$. Captopril increased forearm oxygen extraction $(p<0.05)$ and tended to increase blood flow and thus increased oxygen consumption $(\mathrm{p}<0.01)$ during maximal exercise. Our data indicate that oxygen utilization was impaired in patients with severe $\mathrm{CHF}$ and that captopril improved forearm oxygen utilization during maximal handgrip exercise in patients with severe $\mathrm{CHF}$.

\section{Additional Indexing Words :}

Forearm blood flow Plethysmography

DATIENTS with congestive heart failure (CHF) frequently demonstrate a 1 decrease in exercise capacity, which is probably due to decreased oxygen utilization by working skeletal muscle. ${ }^{1,2)}$ Previous studies have suggested that impaired vasodilatation of working skeletal muscle during exercise was the principal mechanism for the decreased skeletal muscle oxygen utilization. ${ }^{3-6)}$ Increased activity of the renin-angiotensin system in CHF may be one of the factors responsible for the decreased vasodilatory capacity of resistance vessels in CHF. ${ }^{7-9}$ )

It has been shown that captopril improves exercise capacity of patients with CHF.101,11) If exercise capacity depends on oxygen utilization by working skeletal muscle, one may anticipate that captopril improves oxygen consumption of the working skeletal muscle. However two previous studies failed to show a significant improvement of oxygen consumption of the working skeletal muscle in CHF by acute inhibition of the renin-angiotensin system by captopril.12),13) In those studies, several factors might have resulted in the failure of captopril to increase oxygen consumption of the working skeletal muscle in patients with CHF. First, the decrease in systolic blood pressure by captopril was so great that the systolic blood pressure after captopril was at shock level, which might have impaired tissue oxygen utilization. Second, plasma renin activity was not measured in their studies. It is possible that the effects of captopril on regional circulation in muscles may depend on the level of plasma renin activity. ${ }^{14)}$ Accordingly, in this study, systolic blood pressure after captopril was maintained in the physiological range. We also measured plasma renin activity and examined the effects of captopril on oxygen utilization during exercise in patients with $\mathrm{CHF}$ with high and low plasma renin activity. Our study demonstrated that captopril improves oxygen utilization of the working skeletal muscle during maximal handgrip exercise in patients with severe CHF and high plasma renin activity but not in patients with mild CHF and low plasma renin activity. 
Methous

\section{Subjects:}

Studies were performed in patients with chronic CHF and in control subjects. All patients had routine cardiovascular examinations including chest roentgenogram, electrocardiogram, echocardiogram (two-dimensional sector scan and Doppler). All except 1 patient underwent cardiac catheterization. Four patients had dilated cardiomyopathy, 5 patients valvular heart disease, 1 patient cardiac amyloidosis and 1 patient old myocardial infarction. Patients with heart failure were divided into 2 groups according to the level of plasma renin activity and New York Heart Association functional classification (NYHA). Group 1 consisted of 7 normal control subjects ( $48 \pm 2$ years old), group 2, 7 patients with severe CHF ( $53 \pm 4$ years old) and group 3, 4 patients with mild CHF ( $47 \pm 5$ years old). Hemoglobin was $14.5 \pm 0.9$ for group $1,12.0 \pm 0.7$ for group 2 and $14.5 \pm 0.9 \mathrm{~g} / \mathrm{dl}$ for group 3 . Arterial oxygen saturation was $96 \pm 0$ for group 1, 96 \pm 1 for group 2 and $97 \pm 1 \%$ for group 3 . Age, and values of hemoglobin and arterial oxygen saturation were not different among the 3 groups. NYHA functional classification was $3.6 \pm 0.3$ in group 2 and $2 \pm 0$ in group $3(\mathrm{p}<0.01)$. The plasma renin activity was $0.5 \pm 0.2 \mathrm{ng} / \mathrm{ml} / \mathrm{h}$ in group $1,11.3 \pm 3.9 \mathrm{ng} / \mathrm{ml} / \mathrm{h}$ in group 2 and $2.4 \pm 0.2 \mathrm{ng} / \mathrm{ml} / \mathrm{h}$ in group $3(\mathrm{p}<0.01)$. All patients were on digitalis and furosemide but none was taking vasodilators. The study protocol was explained and informed consent was obtained from each subject.

\section{Measurements of forearm blood flow and calculation of oxygen consumption:}

Forearm blood flow (FBF) was measured using a mercury-in-silastic strain gauge plethysmograph with the venous occlusion technique. ${ }^{15), 16}$ ) The strain gauge was placed approximately $5 \mathrm{~cm}$ below the antecubital crease. The pressure of the venous occlusion or congesting cuff was $40 \mathrm{mmHg}$. Circulation to the hand was arrested by inflating a cuff around the wrist to suprasystolic pressure during the determination of forearm blood flow. Forearm blood flow was taken as the average of 4 to 8 flow measurements made at 15 -sec intervals. It has been recognized that the plethysmograph may not measure true blood flow during exercise. In the present study, it was also difficult to measure forearm blood flow during dynamic handgrip exercise. Therefore we used 3 consecutive flow measurements immediately after stopping the cxercise for later analysis, which allowed accurate calculation of blood flow. The blood pressure was measured in the other arm with a sphygmomanometer. Forearm vascular resistance (FVR) was calculated by dividing mean arterial pressure (diastolic pressure plus 
one third of the pulse pressure in millimeters of mercury) by forearm blood flow (milliliters per minute per $100 \mathrm{ml}$ of forearm volume). These values are expressed as "units" throughout this report.

An 18 gauge cannula (Argyll) was inserted into the antecubital vein of the arm to be exercised and the cannula passed percutaneously to the midbrachial vein for the sampling of mixed forearm venous blood for measurements of oxygen saturation. Oxygen saturation and hemoglobin were determined and oxygen content was calculated. Percent oxygen extraction was calculated as the difference of the arterial-venous oxygen content divided by the arterial oxygen content. Forearm oxygen consumption $\left(\mathrm{FVO}_{2}\right)$ was calculated by the Fick principle $\left(\mathrm{FVO}_{2}=\right.$ forearm arterial-venous oxygen difference $($ vol \%) $\times 1.34 \times \mathrm{FBF}(\mathrm{ml} / \mathrm{min} / 100 \mathrm{ml}) \times$ hemoglobin $(\mathrm{g} / \mathrm{dl})$ divided by 100). The radial artery was punctured to obtain arterial oxygen saturation. Arterial puncture was done only one time at rest because handgrip exercise of one side appeared not to alter systemic arterial saturation. All subjects were studied in the basal post absorptive state and allowed to rest for 15-20 min following instrumentation.

\section{Exercise protocol:}

After obtaining basal blood pressure, heart rate, FBF, arterial and venous oxygen saturation, and hemoglobin, the subject performed rhythmic handgrip exercise by squeezing a handgrip tool of $15 \mathrm{~kg}$ resistance 6 times/ min for $4 \mathrm{~min}$. During the last $1 \mathrm{~min}$ of exercise, venous blood was withdrawn for measurements of oxygen saturation. FBF was measured during the last $1 \mathrm{~min}$ of exercise and the first $1 \mathrm{~min}$ after stopping the exercise. Three measurements of FBF during the first minute after stopping exercise were used for further analysis. Several minutes of rest were allowed and then exercise was again performed with $20 \mathrm{~kg}$ resistance of handgrip, 6 times/min for $4 \mathrm{~min}$. Venous blood samples were again withdrawn and FBF was determined. Several minutes of rest were allowed. Then maximal handgrip exercise was performed by squeezing a $20 \mathrm{~kg}$ resistance handgrip tool, 6-24 timcs $/ \mathrm{min}$ for $4 \mathrm{~min}$. The frequency of handgrip exercise was individualized but all subjects performed maximal exercise to the point when they felt fatigue of the exercised arm. Venous blood samples were drawn and FBF was determined.

Captopril study:

Captopril (25 mg, orally) was given to all subjects. All hemodynamic data and blood samples were obtained 1 hour later at rest and during exercise. One hour after captopril administration, exercise was performed. 
The same degrees of exercise as before captopril were performed after captopril.

\section{Plasma renin activity:}

Blood samples were obtained at the time of study for the measurement of plasma renin activity. Mixed venous blood was drawn into a chilled collection tube that contained EDTA. Specimens were immediately centrifuged and the plasma was removed and frozen. Plasma renin activity was measured by radioimmunoassay.

\section{Statistical analysis:}

Clinical and hemodynamic data from control subjects and patients with CHF were compared by unpaired t-test. Data before and after captopril were compared by paired t-test. All values are expressed as mean \pm SEM. $\mathrm{P}<0.05$ was considered statistically significant.

\section{RESULTS}

At rest (Table I):

Subjects' hemodynamic data at rest before captopril are shown in Table I. Systolic $(\mathrm{p}<0.05)$, diastolic $(\mathrm{p}<0.01)$ and mean blood pressure $(\mathrm{p}<0.01)$ were significantly lower in patients with severe CHF than in control subjects. FBF was significantly smaller $(\mathrm{p}<0.05)$ and percent oxygen extraction was significantly greater $(\mathrm{p}<0.05)$ in patients with severe CHF than in control subjects. $\mathrm{FVO}_{2}$ was not different between control subjects and patients with severe CHF. The hemodynamic data of patients with mild $\mathrm{CHF}$ were not different from those of control subjects.

During exercise (Table II and Fig. 1):

In Fig. 1, percent oxygen extraction, FBF, FVR and $\mathrm{FVO}_{2}$ in control subjects and patients with severe CHF during exercise before captopril are shown. Percent oxygen extraction was significantly greater during submaximal exercise $(15 \mathrm{~kg})$ in patients with severe CHF than in control subjects $(p<0.05)$ but was not different during maximal exercise between the 2 groups. FBF was significantly smaller during submaximal $(\mathrm{p}<0.05)$ and maximal $(\mathrm{p}<0.01)$ exercise in patients with severe CHF than in control subjects. FVR was significantly greater during submaximal $(20 \mathrm{~kg})(\mathrm{p}<0.05)$ and maximal $(p<0.01)$ exercise in patients with severe CHF than in control subjects. $\mathrm{FVO}_{2}$ was not different during submaximal exercise between the 2 groups but was significantly smaller $(\mathrm{p}<0.01)$ during maximal exercise in 
Table I. Hemodynamic Data at

\begin{tabular}{|c|c|c|c|c|}
\hline & & $\underset{(\mathrm{mmHg})}{\mathrm{SBP}}$ & $\underset{(\mathrm{mmHg})}{\mathrm{DBP}}$ & $\underset{(\mathrm{mmHg})}{\mathrm{MBP}}$ \\
\hline \multirow{2}{*}{$\begin{array}{l}\text { Control } \\
\text { subjects } \\
(n=7)\end{array}$} & Before captopril & $125 \pm 5$ & $84 \pm 4$ & $97 \pm 4$ \\
\hline & After captopril & $125 \pm 7$ & $82 \pm 5$ & $96 \pm 5$ \\
\hline \multirow{2}{*}{$\begin{array}{l}\text { Patients with } \\
\text { severe CHF } \\
(\mathrm{n}=7)\end{array}$} & Before captopril & $109 \pm 5$ & $66 \pm 4 * *$ & $80 \pm 3 * *$ \\
\hline & After captopril & $97 \pm 6 t$ & $59 \pm 4$ & $72 \pm 4 \dagger$ \\
\hline \multirow{2}{*}{$\begin{array}{l}\text { Patients with } \\
\text { mild CHF } \\
(n=4)\end{array}$} & Before captopril & $111 \pm 8$ & $72 \pm 4$ & $86 \pm 5$ \\
\hline & After captopril & $112 \pm 7$ & $75 \pm 5$ & $88 \pm 6$ \\
\hline
\end{tabular}

$\mathrm{FBF}=$ forearm blood flow $; \mathrm{FVR}=$ forearm vascular resistance $; \mathrm{FVO}_{2}=$ forearm oxygen consumption; $\% \mathrm{O}_{2} \mathrm{EXT}=$ percent oxygen extraction.

Table II. Hemodynamic Data

\begin{tabular}{|c|c|c|c|c|c|c|c|}
\hline & & \multicolumn{3}{|c|}{$\% \mathrm{O}_{2}$ Extraction $(\%)$} & \multicolumn{3}{|c|}{$\mathrm{FBF}(\mathrm{ml} / \mathrm{min} / 100 \mathrm{ml})$} \\
\hline & & 15 & 20 & MAX & 15 & 20 & MAX \\
\hline \multirow{2}{*}{$\begin{array}{l}\text { Control } \\
\qquad(n=7)\end{array}$} & Before & $26.5 \pm 4.9$ & $34.2 \pm 6.5$ & $42.4 \pm 5.8$ & $10.4 \pm 1.1$ & $19.8 \pm 3.2$ & $49.4 \pm 4.0$ \\
\hline & After & $30.4 \pm 6.3$ & $35.6 \pm 6.1$ & $41.5 \pm 5.8$ & $10.3 \pm 1.4$ & $16.2 \pm 2.6$ & $47.8 \pm 9.1$ \\
\hline \multirow{2}{*}{$\begin{array}{l}\text { Severe } \\
\qquad \begin{array}{c}\text { CHF } \\
(n=7)\end{array}\end{array}$} & Before & $47.5 \pm 4.0 * *$ & $49.6 \pm 4.9$ & $52.4 \pm 4.2$ & $7.3 \pm 0.5^{*}$ & $10.6 \pm 1.3^{*}$ & $14.9 \pm 1.1^{* *}$ \\
\hline & After & $41.2 \pm 7.3$ & $51.7 \pm 7.6$ & $58.0 \pm 5.6$ & $7.2 \pm 0.4$ & $11.8 \pm 1.2$ & $18.1 \pm 1.0$ \\
\hline \multirow{2}{*}{$\begin{array}{l}\text { Mild } \\
\qquad \text { GHF } \\
(\mathrm{n}=4)\end{array}$} & Before & $39.1 \pm 8.1$ & $43.2 \pm 7.7$ & $52.7 \pm 10.7$ & $9.1 \pm 1.7$ & $14.3 \pm 2.6$ & $28.0 \pm 4.0$ \\
\hline & After & $40.8 \pm 8.9$ & $45.4 \pm 9.9$ & $52.0 \pm 8.6$ & $9.5 \pm 1.3$ & $13.8 \pm 1.9$ & $25.7 \pm 4.9$ \\
\hline
\end{tabular}

$* \mathrm{p}<0.05$ vs control, ** $\mathrm{p}<0.01$ vs control, $+\mathrm{p}<0.05$ before vs after captopril, $\dagger \dagger \mathrm{p}<0.01$ before vs after captopril.

The number of values during maximal exercise in control subjects and severe CHF was six.

patients with severe CHF than in control subjects. Percent oxygen extraction, FBF, FVR and $\mathrm{FVO}_{2}$ during exercise in patients with mild CHF were not different from those in control subjects (Table II).

Effects of captopril (Tables I and II, and Fig. 2):

Captopril did not change hemodynamics at rest and during exercise in control subjects and patients with mild CHF (Tables I and II). In contrast, captopril lowered systolic $(\mathrm{p}<0.05)$, and mean blood pressure $(\mathrm{p}<$ $0.05)$ at rest in patients with severe CHF. Heart rate was not altered by captopril. Captopril did not change percent oxygen extraction, FBF, FVR and $\mathrm{FVO}_{2}$ in patients with severe $\mathrm{CHF}$ at rest and during submaximal exercise (Table II). During maximal exercise, captopril did not change FBF 
Rest Before and After Captopril

\begin{tabular}{|c|c|c|c|c}
\hline $\begin{array}{c}\mathrm{HR} \\
(\mathrm{bpm})\end{array}$ & $\begin{array}{c}\mathrm{FBF} \\
(\mathrm{ml} / \mathrm{min} / 100 \mathrm{ml})\end{array}$ & $\begin{array}{c}\mathrm{FVR} \\
(\text { units })\end{array}$ & $\begin{array}{c}\% \mathrm{O}_{2} \mathrm{EXT} \\
(\%)\end{array}$ & $\begin{array}{c}\mathrm{FV} \mathrm{V}_{2} \times 10^{-2} \\
(\mathrm{ml} / \mathrm{min} / 100 \mathrm{ml})\end{array}$ \\
\hline $63 \pm 2$ & $6.0 \pm 0.8$ & $18.4 \pm 2.9$ & $9 \pm 2$ & $9 \pm 2$ \\
\hline $59 \pm 2$ & $5.7 \pm 0.6$ & $17.9 \pm 1.8$ & $8 \pm 3$ & $9 \pm 2$ \\
\hline $74 \pm 5$ & $3.5 \pm 0.5^{*}$ & $25.9 \pm 3.6$ & $19 \pm 3 *$ & $10 \pm 2$ \\
\hline $68 \pm 5$ & $3.8 \pm 0.8$ & $23.9 \pm 7.2$ & $17 \pm 4$ & $8 \pm 1$ \\
\hline $70 \pm 3$ & $5.5 \pm 1.5$ & $19.1 \pm 4.7$ & $15 \pm 5$ & $12 \pm 2$ \\
\hline $72 \pm 2$ & $5.8 \pm 1.6$ & $19.8 \pm 5.8$ & $20 \pm 3$ & $22 \pm 7$ \\
\hline
\end{tabular}

* $\mathrm{p}<0.05$ vs control, ${ }^{* *} \mathrm{p}<0.01$ vs control, $+\mathrm{p}<0.05$ before vs after captopril.

during Exercise

\begin{tabular}{|c|c|c|c|c|c}
\hline \multicolumn{3}{|c|}{ FVR (units) } & \multicolumn{3}{|c|}{$F \dot{V O}_{2}(\mathrm{ml} / \mathrm{min} / 100 \mathrm{ml}) \times 10^{-2}$} \\
\hline 15 & 20 & MAX & 15 & 20 & MAX \\
\hline $10.2 \pm 0.8$ & $5.8 \pm 2.1$ & $2.4 \pm 0.2$ & $49 \pm 7$ & $121 \pm 25$ & $386 \pm 50$ \\
\hline $10.3 \pm 1.0$ & $6.9 \pm 0.8$ & $2.6 \pm 0.3$ & $59 \pm 16$ & $107 \pm 27$ & $353 \pm 71$ \\
\hline $11.7 \pm 1.1$ & $8.4 \pm 0.8 *$ & $6.0 \pm 0.4 * *$ & $51 \pm 3$ & $76 \pm 7$ & $124 \pm 17 * *$ \\
\hline $10.8 \pm 0.9$ & $6.9 \pm 0.6$ & $4.6 \pm 0.3$ & $45 \pm 5$ & $94 \pm 11$ & $160 \pm 13$ \\
\hline $10.9 \pm 2.1$ & $7.4 \pm 2.2$ & $3.9 \pm 0.9$ & $74 \pm 25$ & $109 \pm 25$ & $261 \pm 49$ \\
\hline $9.7 \pm 1.7$ & $6.9 \pm 1.4$ & $4.3 \pm 0.8$ & $70 \pm 16$ & $109 \pm 18$ & $248 \pm 58$ \\
\hline
\end{tabular}

Abbreviations are same as in Table $I$.

$15=$ handgrip exercise of $15 \mathrm{~kg}, 20=$ handgrip exercise of $20 \mathrm{~kg}$, MAX $=$ maximal exercise, Before = before captopril, After $=$ after captopril.

but significantly increased percent oxygen extraction $(p<0.05)$, and thus increased $\mathrm{FVO}_{2}$ in patients with severe CHF (Fig. 2).

\section{Discussion}

Our study has demonstrated ${ }^{11}$ that the vasodilatory capacity of forearm resistance vessels and maximal forearm oxygen consumption during exercise were decreased in patients with severe $\mathrm{CHF}^{2)}$ and that captopril improved maximal forearm oxygen consumption during exercise in patients with severe CHF. 

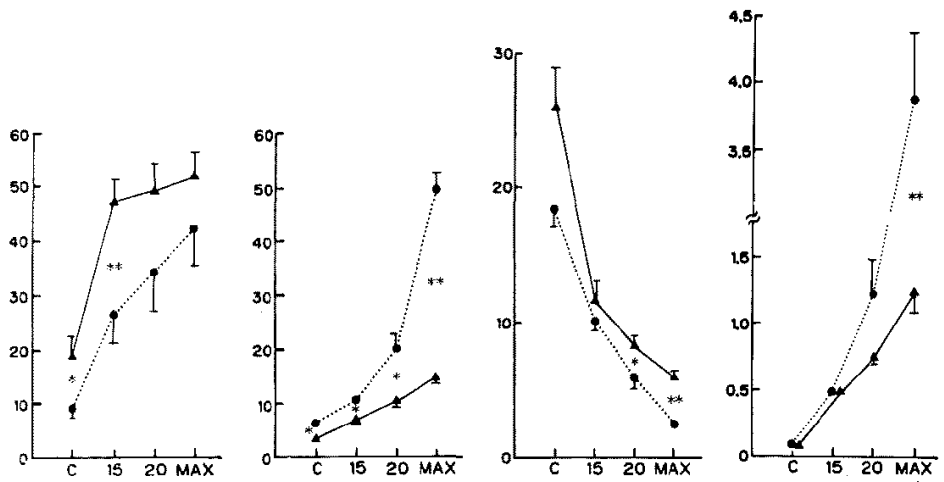

Fig. 1. Percent oxygen extraction (left panel) was significantly greater at rest $(\mathrm{p}<0.05)$ and during submaximal exercise $(5 \mathrm{~kg}, \mathrm{p}<0.01)$ in patients with severe CHF $(n=7)$ than in control subjects $(n=7)$. Forearm blood flow (FBF) (second to the left) was significantly smaller $(p<0.05-0.01)$ in patients with severe CHF than in control subjects at rest and at all levels of exercise. Forearm vascular resistance (FVR) (second to the right) was not different between control subjects and patients with severe CHF at rest and was significantly greater $(\mathrm{p}<0.05-0.01)$ during submaximal $(20 \mathrm{~kg})$ and maximal exercise in patients with severe CHF than in control subjects. Forearm oxygen consumption $\left(\mathrm{FVO}_{2}\right.$ ) (right panel) was not different at rest and during submaximal exercise between control subjects and patients with severe CHF but was significantly smaller during maximal exercise in patients with severe CHF than in control subjects. Closed circles indicate control subjects and closed triangles indicate patients with severe CHF. * indicates $\mathrm{p}<0.05, * *$ indicates $\mathrm{p}<0.01$.
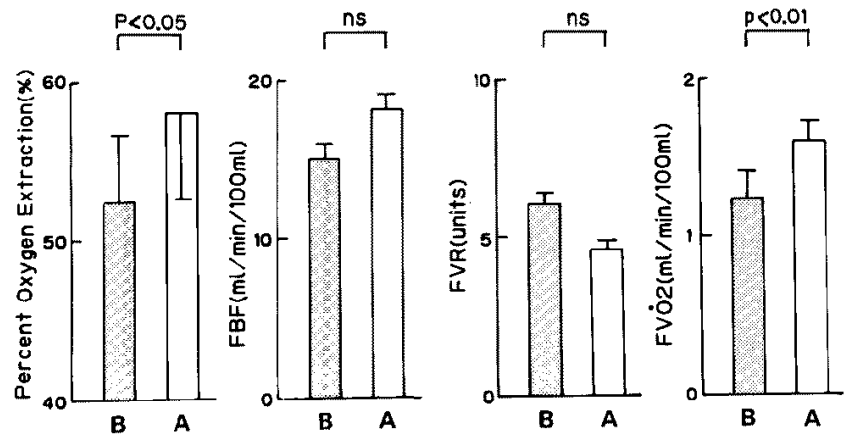

Fig. 2. Changes in percent oxygen extraction, forearm blood flow (FBF), forearm vascular resistance (FVR) and forearm oxygen consumption $\left(\mathrm{FVO}_{2}\right)$ with captopril during maximal cxcrcise in paticnts with scvere CHF. Captopril increased percent oxygen extraction $(p<0.05)$ and forearm oxygen consumption $(p<0.01)$. A: after captopril, B: before captopril. 
Decreased skeletal muscle vasodilatory capacity in patients with $C H F$ :

Previous studies have demonstrated decreased blood flow of the working skeletal muscle in patients with severe $\mathrm{CHF}^{31-6}$. Forearm blood flow measured by strain-gauge plethysmography was significantly smaller at rest and during exercise in patients with severe CHF than in control subjects. The calculated forearm vascular resistance during submaximal and maximal exercise was significantly greater $(p<0.05)$ in patients with severe CHF than in control subjects. These results indicate that skeletal muscle vasodilatory capacity was decreased in patients with severe $\mathrm{CHF}$. These results are consistent with many previous findings obtained by using handgrip ${ }^{4,5}$ or ergometer exercise. ${ }^{3), 61,12), 13)}$

In the present study, forearm blood flow was measured by strain-gauge plethysmography. This technique measures blood flow of the forearm skeletal muscle and skin. Thus decreased forearm blood flow in patients with CHF measured by plethysmography may have resulted from decreased skin blood flow rather than decreased muscle blood flow. Previous studies using epinephrine iontophoresis have indicated that with this method, $50 \%$ of the foream blood flow is to the skin and $50 \%$ to the skeletal muscle in normal subjects as well as in patients with $\mathrm{CHF}^{\left.4{ }^{4},{ }^{17}\right)}$ This may well explain the large but insignificant difference of FVR at rest between normal subjects and patients with severe CHF. However during exercise, muscle blood flow dominates skin blood flow. In addition, Wahren has shown complete separation of forearm musclc and cutancous circulation during strenuous exercise. ${ }^{18}$ Thus increased FVR during exercise in patients with severe CHF was due to decreased vasodilatory capacity of the skeletal muscle rather than the skin.

It has been previously demonstrated that limb resistance vessels do not dilate normally to ischemic stimuli or during exercise in patients with CHF, ${ }^{3)-61,17)}$ Our patients with severe $\mathrm{CHF}$ also had greater forearm vascular resistance during maximal exercise than control subjects. Previous studies suggest that the decreased vasodilatory capacity of resistance vessels in patients with $\mathrm{CHF}$ is due to an increased vascular wall sodium content or interstitial edema. ${ }^{19), 201}$

\section{Decreased oxygen consumption during maximal exercise in patients with CHF:}

In the present study, forearm oxygen consumption was normal at rest and during submaximal exercise of $15 \mathrm{~kg}$, tended to be decreased during submaximal exercise of $20 \mathrm{~kg}$ and was significantly decreased during maximal exercise in patients with severe CHF compared to that in control subjects. Patients with severe CHF had lower forearm blood flow at rest and during 
submaximal exercise than control subjects. However they had greater oxygen extraction, thus maintaining normal or near normal oxygen consumption at rest and during submaximal exercisc. In contrast, during maximal exercise the forearm blood flow was much lower and oxygen extraction was no longer higher and thus maximal oxygen consumption was significantly lower in patients with severe CHF than in control subjects.

Several aspects of the methods deserve consideration. First, in the present study, arterial $\mathrm{O}_{2}$ saturation was obtained only one time to calculate forearm oxygen consumption. If arterial desaturation occurred with handgrip exercise in $\mathrm{CHF}$, calculated forearm oxygen consumption may have been erroneously low. However this possibility is unlikely. It has been shown that exercise by bicycle ergometer, which is more intense than handgrip exercise, did not alter arterial oxygen saturation. ${ }^{2), 3)}$ Second, we introduced a venous catheter from the antecubital vein and positioned it in a deep vein $10 \mathrm{~cm}$ proximal to the antecubital fossa. It is possible that oxygen rich cutaneous blood might have been shunted to deep vein sampling sites. However this possibility was not likely, since Wahren has shown complete separation of forearm muscle and cutaneous circulation during strenuous forearm exercise. ${ }^{18)}$ In addition, Zelis et al have applied epinephrine iontophoresis to suppress skin blood flow during handgrip exercise and have shown that oxygen consumption of the forearm was significantly lower in patients with CHF than in control subjects. ${ }^{17}$ ) Thus decreased forearm oxygen consumption during maximal exercise in patients with severe CHF appears not to have resulted from shunting of the cutaneous blood flow.

The finding of decreased oxygen consumption of the working skeletal muscle in patients with severe CHF in the present study is consistent with previous reports with dynamic and static handgrip exercise and bicycle ergometer. ${ }^{3)-6), 17)}$ Since decreased maximal oxygen consumption of the forearm during exercise resulted from decreased blood flow but not from decreased oxygen extraction, decreased vasodilatory capacity of the resistance vessels appeared to contribute to the decreased oxygen consumption.

\section{Effects of captopril:}

It has been shown that the renin-angiotensin system is activated in CHF ${ }^{8), 9)}$ Our data are consistent with this finding. It also has been shown that the plasma renin activity during exercise is greater in patients with CHF than in normal subjects." Thus it is possible that blocking of the renin-angiotensin system may improve peripheral circulation during exercise in patients with CHF. Previous studies have demonstrated decreases in systemic and regional vascular resistance at rest and during exercise after 
captopril. ${ }^{12)-14\}}$ However, they have failed to find increases in oxygen extraction or oxygen consumption during exercise after captopril. Wilson and Ferraro have found that captopril did not alter leg blood flow, oxygen extraction or oxygen consumption during maximal exercise using an upright bicycle ergometer in patients with CHF. ${ }^{13}$ ) Kugler et al also have reported that captopril decreased oxygen extraction and did not alter femoral venous oxygen content during upright exercise with an ergometer in patients with CHF. ${ }^{12}$ ) In contrast, we found that captopril increased forearm oxygen consumption during maximal exercise in patients with severe CHF which resulted from increased oxygen extraction. These results are consistent with the clinical observation that captopril increases exercise capacity in patients with CHF.

The reasons for the difference in findings between this and previous studies are not clear. However, the level of perfusion pressure after captopril might have been an important factor that caused the difference. The systolic blood pressures after captopril in the studies by Wilson et al and Kugler et al were lower than $80 \mathrm{mmHg}$ whereas it was $97 \mathrm{mmHg}$ in this study. ${ }^{12), 13}$ ) It is possible that low perfusion pressure after captopril in previous studies may have prevented the beneficial effects of captopril on oxygen consumption during maximal exercise. We found an improvement of oxygen consumption during maximal exercise after captopril only in patients who had markedly increased plasma renin activity. In previous studies, plasma renin activity of patients was not presented. Although captopril increased forearm oxygen consumption by $30 \%$ during maximal exercise in patients with severe CHF, it should be noted that oxygen consumption after captopril in these patients was still much lower than that in normal control subjects or in patients with mild CHF.

In summary, blocking the renin-angiotensin system by captopril improved forearm oxygen consumption during maximal exercise in patients with severe CHF and high renin activity. Thus nutritive blood flow to the working skeletal muscle improved, which may account for the finding that captopril increases exercise capacity in patients with CHF.

\section{AGKNOWLEDGMENT}

We appreciate the secretarial assistance of Ms. Mieko Itoyama.

\section{REFERENCES}

1. Weber KT, Kinasewitz GT, Janicki JS, Fishman AP: Oxygen utilization and ventilation during exercise in patients with chronic cardiac failure. Circulation 65: 1213, 1982 
2. Wilson JR, Ferraro N: Exercise intolerance in patients with chronic left heart failure: relation to oxygen transport and ventilatory abnormalities. Am J Gardiol 51 : 1358, 1983

3. Wilson JR, Martin JL, Schwartz D, Ferraro N: Exercise intolerance in patients with chronic heart failure: role of impaired nutritive flow to skeletal muscle. Circulation 69: 1079, 1984

4. Zelis R, Longhurst J, Capone RJ, Mason DT: A comparison of regional blood flow and oxygen utilization during dynamic forearm exercise in normal subjects and patients with congestive heart failure. Circulation 50: 137, 1974

5. Longhurst $\mathrm{J}$, Gifford W, Zelis R: Impaired forearm oxygen consumption during static exercise in patients with congestive heart failure. Circulation 54: 477, 1976

6. LeJemtel TH, Maskin CS, Lacido D, Chadwick B: Failure to augment maximal limb blood flow in response to one-leg versus two-leg exercise in patients with severe heart failure. Circulation 74: 245,1986

7. Hesse B, Christensen NJ, Anderson ED: Renin release in relation to plasma noradrenaline during supine exercise in cardiac patients. Acta Med Scand 204: 185, 1978

8. Curtiss G, Cohn JN, Vrobel T, Franciosa JA: Role of the renin-angiotensin system in the systemic vasoconstriction of chronic congestive heart failure. Circulation 58: 763, 1978

9. Gavras H, Faxon DP, Berkoben J, Brunner HR, Ryan T: Angiotensin converting enzyme inhibition in patients with congestive heart failure. Circulation 58: 770, 1978

10. Mancini DM, Davis L, Wexler JP, Chadwick B, LeJemtel TH: Dependence of enhanced maximal exercise performance on increased peak skeletal muscle perfusion during long-term captopril therapy in heart failure. J Am Coll Cardiol 10: 845, 1987

11. Kramer BL, Massie BM, Topic N: Controlled trial of captopril in chronic heart failure: a rest and exercise hemodynamic study. Circulation 67: 807, 1983

12. Kugler J, Maskin G, Frishmen WH, Sonnenblick EH, LeJemtel TH: Regional and systemic metabolic effects of angiotensin-converting enzyme inhibition during exercise in patients with severe heart failure. Circulation 66: 1256, 1982

13. Wilson JR, Ferraro N: Effects of the renin-angiotensin system on limb circulation and metabolism during exercise in patients with heart failure. J Am Coll Cardiol 6: 556, 1985

14. Kubo S, Nishioka A, Nishimura H, Kawamura K, Takatsu T: Effects of captopril on cardiorenal hemodynamics in patients with severe chronic congestive heart failure. Clin Exp Hyp-Theory and Practice A9: 575, 1987

15. Takeshita A, Imaizumi $T$, Ashihara $T$, Nakamura $M$ : Characteristics of responses to salt loading and deprivation of hypertensive subjects, Circ Res 51:457, 1982

16. Imaizumi $T$, Takeshita $A$, Ashihara $T$, Nakamura $M$ : The effects of sublingual nitroglycerin on forearm vascular resistance in patients with heart failure and normal subjects. Circulation 72: 747,1985

17. Zelis R, Mason DT, Braunwald E: Partition of blood flow to the cutaneous and muscular beds of the forearm at rest and during leg exercise in normal subjects and in patients with heart failure. Circ Res 24: 799, 1969

18. Wahren J: Quantitative aspects of blood flow and oxygen uptake in the human forearm during rhythmic exercise. Acta Physiol Scand 67 (suppl 269): 5, 1966

19. Zelis R, Mason DT, Braunwald E: A comparison of the effects of vasodilator stimuli on peripheral resistance vessels in normal subjects and in patients with congestive heart failure, J Clin Invest 47: 960, 1968

20. Zelis R, Flaim SF: Alterations in vasomotor tone in congestive heart failure. Prog Cardiovasc Dis 24: 437, 1982 